\title{
Informational Mismatches: A Neglected Threat of Climate Change to Interspecific Interactions
}

\author{
Deseada Parejo ${ }^{1,2 *}$ \\ ${ }^{1}$ Área de Zoología, Departamento de Anatomía, Biología Celular y Zoología, Facultad de Ciencias, Universidad de \\ Extremadura, Badajoz, Spain, ${ }^{2}$ Departamento de Ecología Evolutiva y Funcional, Estación Experimental de Zonas Áridas, \\ CSIC, Almería, Spain
}

Interspecific interactions are deeply affected by the current scenario of climate change. This is because interactions are sensitive to many traits of interacting species as phenology, distribution, behavior, and relative abundances which may be differently influenced by climate change in each species. In this scenario, positive interactions, which require temporal coordination of events of life history of interacting species, could be particularly altered due to differential effects of climate change on phenology, apart from by the effects on abundance and distribution. Hitherto, studies focusing on the effects of climate change on positive biotic interactions are scarce and mainly focused on plant-pollinator interactions. Here I propose that, by inducing informational mismatches, climate change may lead to individuals from competing species relying on heterospecific social information to making mis- or un-informed decisions. The idea is that competing species are valuable sources of social information to each other provided overlap of their activities occurs. However, whenever coordination of events fails, competing species will co-occur at the wrong moment, co-occur only in small numbers or even not co-occur at all and thus they will not be able to access useful or any social information from heterospecifics. In that scenario, interacting species would be mis- or un- informed, and, consequently, decision taking will be impaired, leading to disequilibrium in the community. Throughout the manuscript, I will develop the idea of mismatches of information and illustrate it with some case studies.

Keywords: biotic interactions, climate change, competition, informational mismatches, interspecific social information

\section{INTRODUCTION}

Biotic interactions are the basis of many essential functions in ecosystems so that their reduction or loss may affect community composition and, thus, biodiversity (Diaz et al., 2013). And many interactions such as predation, parasitism, or pollination have shown to be very sensitive to anthropogenic changes (Hegland et al., 2009). But despite their importance for biodiversity (Bascompte et al., 2006) and their sensitivity to human-induced changes (Hegland et al., 2009), interactions are often disregarded when analysing the health of ecosystems (Tylianakis et al., 2010).

During the last century, the climate of the Earth has dramatically changed so that the rate of warming has been the highest compared to any other period during the last 1000 years (IPCC, 2001). Evidence strongly supports the huge impact of this recent climate change on organisms 
from different taxa, and geographical distribution (Hughes, 2000; Wuethrich, 2000), affecting their phenology, physiology, and their distribution.

Interspecific interactions are one of the most neglected topics when studying the consequences of climate change, perhaps due to the complexity of their study (McCann, 2007; but see Tylianakis et al., 2008). However, interactions are likely to be very susceptible to climate change, as they are sensitive to the phenology, distribution, behavior, physiology, and relative abundances of multiple species (Suttle et al., 2007; Tylianakis et al., 2007), and the response of each species to climate change may widely differ (Tylianakis et al., 2008). In particular, speciesspecific changes in phenology may cause temporal mismatches because interacting species such as predators and prey, plants and pollinators, or competitors might be active at different times (Visser and Both, 2005). In addition, climate change is expected to induce shifts in the distribution of species as a consequence of species' tracking of their optimal habitats (Kelly and Goulden, 2008). This effect is likely to be species-specific and might hence affect interspecific interactions by either favoring or preventing species occurrence (Urban et al., 2012). Also, climate may differentially affect the survival and reproduction of interacting species so that their population densities may change either in parallel or in opposite direction (Ahola et al., 2007; Hegland et al., 2009), which could lead respectively to an increase or a reduction in competition. Therefore, climate change ultimately impacts on ecosystems affecting the composition of communities through effects on frequency of interactions (Walther et al., 2002).

Here I propose that, by inducing informational mismatches, climate change may affect pairs of competing species that positively interact through social information use. Social information is extracted from interactions with, or observations of, other individuals (Wagner and Danchin, 2010). Social information use is potentially a fast and inexpensive way of assessing local resources and threats and, thus, may enormously affect individual fitness (but see Giraldeau et al., 2002; Seppanen et al., 2007; Schmidt et al., 2010). Social information use is one facilitative mechanism that may promote competitors' coexistence by countering the negative effects of competition (Parejo et al., 2005; Parejo and Avilés, in press), and, hence, promote biodiversity (McIntire and Fajardo, 2014). The idea is that competing species are sources of useful social information to each other provided overlap of their activities occurs. However, whenever coordination of events fails, competing species will cooccur at the wrong moment, or co-occur only in small numbers or even not co-occur at all, and thus they will not be able to access useful or any social information from heterospecifics. In that scenario, interacting species would be, respectively, mis- or un-informed, which may induce individuals to make decisions with inaccurate information on the environment and, consequently, may affect individual fitness (Blanchet et al., 2010). This is what I call an informational mismatch, which might be defined as the de-alignment of production and gathering of information. This mismatch may be temporal, spatial, or quantitative, so that production and gathering of information may be separated in time, in space or the amount of produced and needed information be unbalanced. As a result of the informational mismatch the equilibrium of the community may be affected, because opportunities to use valid social information will be reduced or lost, leading to mis- or uninformed decisions. Simultaneously, the level of interspecific competition might also decrease, which could be positive to interacting species or lead to unexpected collateral effects such as the occurrence of new competitive relationships or the increase of intraspecific competition (Thackeray et al., 2010), i.e., to a change in equilibrium conditions. This scenario is likely to bring consequences on biodiversity and on the functioning of ecosystems.

\section{INTERSPECIFIC SOCIAL INFORMATION USE VS. OTHER POSITIVE INTERACTIONS}

Positive interactions can be defined as all non-consumer interactions among species, which positively affect at least one of the involved species (Bertness and Callaway, 1994). They include facilitations (for example those occurring through the amelioration of abiotic stress by one plant species to another), and mutualisms (for example those established between pollinators and plants or between cleaner fishes and clients). But beyond these two well-known beneficiary mechanisms, competitors can also positively interact by using information provided by heterospecifics on shared limiting factors as resources and predators, i.e., sharing interspecific social information. This is because only competitors may provide valuable information on shared limiting factors (Parejo et al., 2005). And, in some instances, the positive effects of social information use in fitness-affecting decisions may counter the negative effects of competition (Parejo and Avilés, in press).

Positive interactions, in particular, are especially prone to be broken via differential phenological changes. This is so because positive interactions require temporal matching of events of life history of interacting species, probably reducing the benefits when such coordination fails (Rafferty et al., 2015). Therefore, positive interactions are as sensitive as other interactions to altered abundance and distribution of interacting species, but likely to be more sensitive to phenological mismatches caused by climate change. Despite this and the abundance of positive interactions in natural systems (Bronstein, 2009), studies focusing on the effects of climate change on positive biotic interactions are scarce (Hegland et al., 2009), and most of research has targeted on plant-pollinator phenological mismatches (McKinney et al., 2012; Burkle et al., 2013; Rafferty et al., 2015). However, there are surprisingly few studies on other phenological mismatches (Rafferty et al., 2015), and even less on spatial mismatches (Schweiger et al., 2008), between organisms that positively interact, which is what I present here.

Positive interactions among competing species show the particularity that may be two-fold affected by climate change. Climate change may, on the one hand, remove or exacerbate competition, by altering either the temporal (Visser and Both, 2005), or spatial overlapping (Kelly and Goulden, 2008; Telleria et al., 2016) of competitors and/or their population densities (Ahola et al., 2007; Brotons and Jiguet, 2010). On the other 
hand, climate change may also affect the positive side of the interaction, i.e., the value of social information, by changing the moment and/or the place in which it is produced, and the amount and/or quality of produced information as well. Firstly, whenever social information is produced in a decoupled manner in time or space, information collectors will be uninformed. Second, social information to be reliable needs to be produced by a significant group of informed individuals, therefore, when information is provided by only a small sample of informers, individuals gathering information may become misinformed. Therefore, the impact of climate change on positive interactions among competitors is expected to have unforeseen and more complex consequences compared to classical positive interactions where the informational side is absent.

This proposal is original because this is the first time, to my knowledge, that availability of social information in the environment is proposed to be affected by a mismatch due to climate change, which differs radically from services or resources whose mismatch have been studied so far (Diaz et al., 2013). Moreover, here the effect of climate change on interspecific interactions among competitors is explained considering the reciprocal nature of these interactions. That is, I propose that interspecific interactions among competitors may be affected by climate change two-fold: (1) through its effects on availability of social information by alteration of the phenology, abundance and distribution of interacting species; and (2) through its effects on competition. Meanwhile, previous studies considered only the effects of climate change on the intensity of competition (Ahola et al., 2007; Stenseth et al., 2015; Wittwer et al., 2015)

\section{PAIRS OF RESIDENT-MIGRANT BIRDS AS STUDY MODELS OF A PHENOLOGICAL INFORMATIONAL MISMATCH}

A system in which a resident bird species provides useful social information on breeding quarters to a migratory one constitutes an excellent model to investigate how climate change may promote phenological mismatches between positively interacting organisms. Residents are better informed on breeding habitats than migrants as a consequence of the longer available time-window during which they can evaluate limiting factors (Monkkönen et al., 1990). On their side, migratory birds are timelimited in their decision-making because they arrive to breeding quarters later in the season. Consequently, when assessing breeding habitat quality, migratory birds can take a short- cut and rely on social information provided by competing resident species.

However, phenological responses to environmental variation differ among species (Visser and Both, 2005), so that over the last decades some species, populations or individuals have advanced their seasonal activities (Hughes, 2000; Walther et al., 2002; Charmantier et al., 2008; Husby et al., 2010) and others show no shift in phenology in response to climate change due to their inability to track changes (Visser et al., 1998, 2003; Nussey et al., 2005; Both et al., 2006; Lane et al., 2012). These differences are more patent between resident and migratory birds due to their different flexibilities to adjust themselves to environmental changes (Both et al., 2006, 2010; Moller et al., 2008; Wittwer et al., 2015). Indeed, long-distance migrants are more vulnerable than residents to mismatches due to global change because they cannot predict changes in breeding quarters while spending the winter in distant wintering sites. Therefore, long-distance migrants show less flexibility to changes than short-distance migrant (Lehikoinen et al., 2004; Rubolini et al., 2007; Both et al., 2010) and resident species (Both et al., 2010). Differences in migratory status may, hence, lead to a climate change scenario in which the phenology of resident birds will have been adjusted to environmental changes and much less the phenology of their competitor migrants (Walther, 2010). This will induce an informational mismatch because migrants will not be able to easily acquire social information from residents due to the advancement of residents' breeding and thus of social information. Migratory species will be thus miss- or un-informed whereas residents will be favored by a softened competition with migrants (Ahola et al., 2007). This scenario of information mistiming adds to the already known phenological mistiming occurring between offspring's demands and peak food abundance, occurring when shifts in birds' breeding phenology are not as large as that of their prey (Visser and Both, 2005; Both et al., 2009).

For instance, long-term nest-box studies on insectivorous tits (Paridae) and flycatchers (Ficedula sp.) have been largely used as examples of different responses to climate change within an ecosystem. Both tits and flycatchers depend on caterpillars to feed their offspring and hence should adjust their nestling period to the peak of caterpillar abundance. In many of these studies, breeding phenology of tits and flycatchers and caterpillars' abundance advanced in response to increases in spring temperatures (Winkel and Hudde, 1997; McCleery and Perrins, 1998; Visser et al., 1998; Slater, 1999; Both and Visser, 2001; Sanz et al., 2003; Both et al., 2009; Goodenough et al., 2010). However, as sensitivity to changes is speciesspecific, the magnitude of the effect of climate change differs for tits, flycatchers and caterpillars. Both tits and flycatchers suffer the mismatch with their main food because caterpillars are able to track changes more precisely, but resident tits seem to better adjust their phenology to caterpillars than flycatchers (Visser et al., 1998, 2012; Both and Visser, 2001). In many instances, this mismatch with caterpillars' peak has been done responsible of all the negative effects on birds' fitness. However, apart from sharing caterpillars as the main food, tits and flycatchers also share nest-sites and predators during the breeding season, i.e., they are competitors for food, nest-sites and free-enemy space. Resident tits start the reproduction earlier than migratory flycatchers, which arrive later to breeding patches and have to evaluate their quality fast before reproduction. There are many pieces of evidence showing that the bad-informed flycatchers, instead of directly assessing breeding habitat quality on their own, they actually do use social information from tits to make informed breeding decisions (Forsman et al., 2002, 2007; Loukola et al., 2013). But tits and flycatchers phenologies are likely to be differently affected by climate change, which would cause an informational mismatch 
between informer and informed individuals. Therefore, it is possible that informational mismatches produce additive negative effects difficult to distinguish from food effects. Climate change, hence, may affect tits and flycatchers by any of the two described mechanisms, i.e., food or informational mismatch, or by the additive or interactive effect of the two. Only an experiment manipulating the moment in which social information is provided would allow to disentangle between the two possibilities (mismatch between birds and their prey or between well-informed resident and bad-informed migratory birds) or to establish the relative importance of each factor. By artificially advancing, delaying or maintaining the time when the informer species provides useful social information to the non-informed species before the breeding season in different patches, it is possible to know whether breeding habitat selection by the informed species is affected by informational mismatches. This could be done, for instance, by artificially manipulating breeding tit densities at different moments during the spring in the different patches. Tit density may be modified by using artificial nests appearing tit nests with completed clutches (as in Forsman et al., 2012). If flycatchers are affected by the informational mismatch with tits, they are expected not to respond to advanced and delayed social information because they, respectively, either are not able to access to social information due to their later arrival to breeding quarters, or social information is provided later than needed, when they have started reproduction. On the contrary, flycatchers are expected to respond to social information provided in patches where there is no informational mismatch (i.e., where social information is provided as usually happened in nature). If the problem of flycatchers is the food mismatch, however, nest-site selection should be similar in patches under the different treatments of social information. So far, most studies analysing the impact of climate change on interspecific synchrony have been based on correlative long-term data sets, which, despite their importance and interest to deepen in natural patterns, prevent determining the causality of the found patterns.

The general prediction emerging from the idea that less plastic migratory birds will become misinformed under a climate change scenario is that they will suffer the consequences of climate change more severely than resident birds. Previous studies have suggested that a trophic mismatch due to climate change may help explaining widespread population decline of long-distance migratory birds in Europe (Sanderson et al., 2006; Heldbjerg and Fox, 2008). However, the known decline of European longdistance migrants (Berthold et al., 1998) might be also attributed to a mismatch of information production, or, most probably, to the additive or interactive effects of the trophic and informational mismatches.

\section{OTHER POSSIBLE STUDY MODELS OF INFORMATIONAL MISMATCHES}

Apart from phenological mismatches, climate change may render other impacts on animal populations as on their distribution (Urban et al., 2012) and/or abundance (Ahola et al., 2007). Therefore, two competitor species sharing social information whose distribution or population density were differently affected by the increasing temperature may serve to illustrate other informational mismatches due to climate change.

Indeed, as average temperature increases, optimum habitat for many species will move higher up mountains or further toward the Poles. Whenever, the distribution of the informant species was modified and not that of the informed, the overlapping area for the two species will either be reduced or disappear, leading to a situation where social information will be scarce or absent. This could happen, for instance, when the informant species is an specialist, whose distribution is likely to be more affected by the increasing temperature, and the informed is a generalist, and hence less sensitive to changes. Additionally, an informational mismatch may occur as well when climate change particularly affects the population density of one of the interacting species because, for instance, it performs better in cold environments. If this species is the informer in the system, the decreased population density would lead to a decrease in the quality of social information and hence to a misinformed situation.

\section{CONCLUSIONS}

The present biodiversity crisis may be exacerbated by the deeply and so far overlooked impact that climate change may have on interspecific interactions. Losing interactions involves the loss of ecological functions and hence the "health" of ecosystems (Valiente-Banuet et al., 2015). In particular, positive interspecific interactions are likely to be very sensitive to climate change (Rafferty et al., 2015). Here I propose that climate change, by altering the phenology, distribution and abundance of some species but not of others, might reduce or completely remove the overlapping between competing species using interspecific social information and, hence, induce an informational mismatch. The mismatch might lead to individuals from the species relying on heterospecific social information to making mis- or un-informed decisions. As a result, the relationships between interacting species will be altered through the alteration of the competitive balance, and, consequently, the equilibrium of the community.

The suggested effects of climate change on informational mismatches may be well broadened to general anthropogenic changes provided they induce a species-specific alteration of phenology, abundance, and/or distribution. Indeed, there are examples showing differential effects of urbanization on competing species (Chace and Walsh, 2006; Carrete et al., 2009), which could induce informational mismatches whenever competitors shared social information.

\section{AUTHOR CONTRIBUTIONS}

DP conceived and developed the main idea of the manuscript. DP also wrote the manuscript. 


\section{FUNDING}

The research of the author was supported by the Spanish Ministry of Education and Science/FEDER through the projects CGL201127561/BOS and CGL2014-56769-P. The contract of the author was supported by the Government of Extremadura by the TA13002 while writing.

\section{REFERENCES}

Ahola, M. P., Laaksonen, T., Eeva, T., and Lehikoinen, E. (2007). Climate change can alter competitive relationships between resident and migratory birds. $J$. Anim. Ecol. 76, 1045-1052. doi: 10.1111/j.1365-2656.2007.01294.x

Bascompte, J., Jordano, P., and Olesen, J. M. (2006). Asymmetric coevolutionary networks facilitate biodiversity maintenance. Science 312, 431-433. doi: 10.1126/science. 1123412

Berthold, P., Fiedler, W., Schlenker, R., and Querner, U. (1998). 25-year study of the population development of central European songbirds: a general decline most evident in long-distance migrants. Naturwissenschaften 85, 350-353. doi: 10.1007/s001140050514

Bertness, M. D., and Callaway, R. (1994). Positive interactions in communities. Trends Ecol. Evol. 9, 191-193. doi: 10.1016/0169-5347(94)90088-4

Blanchet, S., Clobert, J., and Danchin, E. (2010). The role of public information in ecology and conservation: an emphasis on inadvertent social information. Ann. N.Y. Acad. Sci. 1195, 149-168. doi: 10.1111/j.1749-6632.2010. 05477.x

Both, C., Bouwhuis, S., Lessells, C. M., and Visser, M. E. (2006). Climate change and population declines in a long-distance migratory bird. Nature 441, 81-83. doi: 10.1038/nature04539

Both, C., and Visser, M. E. (2001). Adjustment to climate change is constrained by arrival date in a long-distance migrant bird. Nature 411, 296-298. doi: $10.1038 / 35077063$

Both, C., van Asch, M., Bijlsma, R. G., van den Burg, A. B., and Visser, M. E. (2009). Climate change and unequal phenological changes across four trophic levels: constraints or adaptations? J. Anim. Ecol. 78, 73-83. doi: 10.1111/j.13652656.2008.01458.x

Both, C., Van Turnhout, C. A., Bijlsma, R. G., Siepel, H., Van Strien, A. J., and Foppen, R. P. (2010). Avian population consequences of climate change are most severe for long-distance migrants in seasonal habitats. Proc. R. Soc. B Biol. Sci. 277, 1259-1266. doi: 10.1098/rspb.2009.1525

Bronstein, J. L. (2009). The evolution of facilitation and mutualism. J. Ecol. 97, 1160-1170. doi: 10.1111/j.1365-2745.2009.01566.x

Brotons, L., and Jiguet, F. (2010). "Bird communities and climate change," in Effects of Climate Change on Birds, eds A. P. Moller, F. Wolfgang, and P. Berthold (New York, NY: Oxford University Press), 275-294.

Burkle, L. A., Marlin, J. C., and Knight, T. M. (2013). Plant-pollinator interactions over 120 years: loss of species, co-occurrence, and function. Science 339, 1611-1615. doi: 10.1126/science. 1232728

Carrete, M., Tella, J. L., Blanco, G., and Bertellotti, M. (2009). Effects of habitat degradation on the abundance, richness and diversity of raptors across Neotropical biomes. Biol. Conserv. 142, 2002-2011. doi: 10.1016/j.biocon.2009.02.012

Chace, J. F., and Walsh, J. J. (2006). Urban effects on native avifauna: a review. Landsc. Urban Plan. 74, 46-69. doi: 10.1016/j.landurbplan.2004.08.007

Charmantier, A., McCleery, R. H., Cole, L. R., Perrins, C., Kruuk, L. E. B., and Sheldon, B. C. (2008). Adaptive phenotypic plasticity in response to climate change in a wild bird population. Science 320, 800-803. doi: 10.1126/science.1157174

Diaz, S., Purvis, A., Cornelissen, J. H., Mace, G. M., Donoghue, M. J., Ewers, R. M., et al. (2013). Functional traits, the phylogeny of function, and ecosystem service vulnerability. Ecol. Evol. 3, 2958-2975. doi: 10.1002/ece3.601

Forsman, J. T., Seppanen, J. T., and Monkkönen, M. (2002). Positive fitness consequences of interspecific interaction with a potential competitor.

\section{ACKNOWLEDGMENTS}

I thank J. M. Avilés for their helpful comments on the paper and Óscar Gordo for discussing general ideas about phenological mismatches and climate change. Also, I am very grateful to an anonymous referee and Dr. Wiebke Schuett for the constructive review of the manuscript.

Proc. R. Soc. Lond. B Biol. Sci. 269, 1619-1623. doi: 10.1098/rspb. 2002.2065

Forsman, J. T., Seppanen, J. T., and Nykanen, I. L. (2012). Observed heterospecific clutch size can affect offspring investment decisions. Biol. Lett. 8, 341-343. doi: 10.1098/rsbl.2011.0970

Forsman, J. T., Thomson, R. L., and Seppanen, J. T. (2007). Mechanisms and fitness effects of interspecific information use between migrant and resident birds. Behav. Ecol. 18, 888-894. doi: 10.1093/beheco/arm048

Giraldeau, L.-A., Valone, T., and Templenton, J. J. (2002). Potencial disadvantages of using socially adquired information. Phil. Trans. R. Soc. Lond. B Biol. Sci. 357, 1559-1566. doi: 10.1098/rstb.2002.1065

Goodenough, A. E., Hart, A. G., and Stafford, R. (2010). Is adjustment of breeding phenology keeping pace with the need for change? Linking observed response in woodland birds to changes in temperature and selection pressure. Clim. Change 102, 687-697. doi: 10.1007/s10584-010-9932-4

Hegland, S. J., Nielsen, A., Lazaro, A., Bjerknes, A. L., and Totland, O. (2009). How does climate warming affect plant-pollinator interactions? Ecol. Lett. 12, 184-195. doi: 10.1111/j.1461-0248.2008.01269.x

Heldbjerg, H., and Fox, T. (2008). Long-term population declines in Danish trans-Saharan migrant birds. Bird Study 55, 267-279. doi: $10.1080 / 00063650809461532$

Hughes, L. (2000). Biological consequences of global warming: is the signal already apparent? Trends Ecol. Evol. 15, 56-61. doi: 10.1016/S0169-5347(99)01764-4

Husby, A., Nussey, D. H., Visser, M. E., Wilson, A. J., Sheldon, B. C., and Kruuk, L. E. B. (2010). Contrasting patterns of phenotypic plasticity in reproductive traits in two great tit (parus major) populations. Evolution 64, 2221-2237. doi: 10.1111/j.1558-5646.2010.00991.x

IPCC (2001). Climate Change 2001: The Scientific Basis. Cambridge, UK: Cambridge University Press.

Kelly, A. E., and Goulden, M. L. (2008). Rapid shifts in plant distribution with recent climate change. Proc. Natl. Acad. Sci. U.S.A. 105, 11823-11826. doi: 10.1073/pnas.0802891105

Lane, J. E., Kruuk, L. E., Charmantier, A., Murie, J. O., and Dobson, F. (2012). Delayed phenology and reduced fitness associated with climate change in a wild hibernator. Nature 48, 554-557. doi: 10.1038/nature11335

Lehikoinen, E., Sparks, T. H., and Zalakevicius, M. (2004). Arrival and departure dates. Adv. Ecol. Res. 35, 1-31. doi: 10.1016/S0065-2504(04)35001-4

Loukola, O. J., Seppanen, J. T., Krams, I., Torvinen, S. S., and Forsman, J. T. (2013). Observed fitness may affect niche overlap in competing species via selective social information use. Am. Nat. 182, 474-483. doi: 10.1086/671815

McCann, K. (2007). Protecting biostructure. Nature 446, 29. doi: 10.1038/446029a

McCleery, R. H., and Perrins, C. M. (1998). ...temperature and egg-laying trends. Nature 391, 30-31. doi: 10.1038/34073

McIntire, E. J., and Fajardo, A. (2014). Facilitation as a ubiquitous driver of biodiversity. New Phytol. 201, 403-416. doi: 10.1111/nph.12478

McKinney, A. M., CaraDonna, P. J., Inouye, D. W., Barr, B., Bertelsen, C., and Waser, N. M. (2012). Asynchronous changes in phenology of migrating Broadtailed Hummingbirds and their early-season nectar resources. Ecology 93, 1987-1993. doi: 10.1890/12-0255.1

Moller, A. P., Rubolini, D., and Lehikoinen, E. (2008). Populations of migratory bird species that did not show a phenological response to climate change are declining. Proc. Natl. Acad. Sci. U.S.A. 105, 16195-16200. doi: 10.1073/pnas.0803825105

Monkkönen, M., Helle, P., and Soppela, K. (1990). Numerical and behavioralresponses of migrant passerines to experimental manipulation of resident tits 
(Parus spp.) - heterospecific attraction in Northern breeding bird communities. Oecologia 85, 218-225. doi: 10.1007/BF00319404

Nussey, D. H., Postma, E., Gienapp, P., and Visser, M. E. (2005). Selection on heritable phenotypic plasticity in a wild bird population. Science 310, 304-306. doi: $10.1126 /$ science.1117004

Parejo, D., and Avilés, J. M. (in press). Social information use by competitors: resolving the enigma of species coexistence in animals? Ecosphere.

Parejo, D., Danchin, E., and Avilés, J. M. (2005). The heterospecific habitat copying hypothesis: can competitors indicate habitat quality? Behav. Ecol.16, 96-105. doi: 10.1093/beheco/arh136

Rafferty, N. E., CaraDonna, P. J., and Bronstein, J. L. (2015). Phenological shifts and the fate of mutualisms. Oikos 124, 14-21. doi: 10.1111/oik. 01523

Rubolini, D., Ambrosini, R., Caffi, M., Brichetti, P., Armiraglio, S., and Saino, N. (2007). Long-term trends in first arrival and first egg laying dates of some migrant and resident bird species in Northern Italy. Int. J. Biometeorol. 51, 553-563. doi: 10.1007/s00484-007-0094-7

Sanderson, F. J., Donald, P. F., Pain, D. J., Burfield, I. J., and van Bommel, F. P. J. (2006). Long-term population declines in Afro-Palearctic migrant birds. Biol. Conserv. 131, 93-105. doi: 10.1016/j.biocon.2006.02.008

Sanz, J. J., Potti, J., Moreno, J., Merino, S., and Frias, O. (2003). Climate change and fitness components of a migratory bird breeding in the mediterranean region. Glob. Change Biol. 9, 461-472. doi: 10.1046/j.1365-2486.2003. 00575.x

Schmidt, K. A., Dall, S. R. X., and van Gils, J. A. (2010). The ecology of information: an overview on the ecological significance of making informed decisions. Oikos 119, 304-316. doi: 10.1111/j.1600-0706.2009.17573.x

Schweiger, O., Settele, J., Kudrna, O., Klotz, S., and Kuhn, I. (2008). Climate change can cause spatial mismatch of trophically interacting species. Ecology 89, 3472-3479. doi: 10.1890/07-1748.1

Seppanen, J. T., Forsman, J. T., Monkkonen, M., and Thomson, R. L. (2007). Social information use is a process across time, space, and ecology, reaching heterospecifics. Ecology 88, 1622-1633. doi: 10.1890/06-1757.1

Slater, F. M. (1999). First-egg date fluctuations for the pied flycatcher ficedula hypoleuca in the woodlands of mid-Wales in the twentieth century. Ibis 141, 497-499. doi: 10.1111/j.1474-919X.1999.tb04420.x

Stenseth, N. C., Durant, J. M., Fowler, M. S., Matthysen, E., Adriaensen, F., Jonzén, N., et al. (2015). Testing for effects of climate change on competitive relationships and coexistence between two bird species. Proc. R. Soc. B Biol. Sci. 282:20141958. doi: 10.1098/rspb.2014.1958

Suttle, K., Thomsen, M. A., and Power, M. E. (2007). Species interactions reverse grassland responses to changing climate. Science 315, 640-642. doi: $10.1126 /$ science. 1136401

Telleria, J. L., Fernandez-Lopez, J., and Fandos, G. (2016). Effect of climate change on mediterranean winter ranges of two migratory passerines. PLoS ONE 11:e0146958. doi: 10.1371/journal.pone.0146958

Thackeray, S. J., Sparks, T. H., Frederiksen, M., Burthe, S., Bacon, P. J., Bell, J. R. et al. (2010). Trophic level asynchrony in rates of phenological change for marine, freshwater and terrestrial environments. Glob. Change Biol. 16, 3304-3313. doi: 10.1111/j.1365-2486.2010.02165.x

Tylianakis, J. M., Didham, R. K., Bascompte, J., and Wardle, D. A. (2008). Global change and species interactions in terrestrial ecosystems. Ecol. Lett. 11, 1351-1363. doi: 10.1111/j.1461-0248.2008.01250.x
Tylianakis, J. M., Laliberte, E., Nielsen, A., and Bascompte, J. (2010). Conservation of species interaction networks. Biol. Conserv. 143, 2270-2279. doi: 10.1016/j.biocon.2009.12.004

Tylianakis, J. M., Tscharntke, T., and Lewis, O. T. (2007). Habitat modification alters the structure of tropical host-parasitoid food webs. Nature 445, 202-205. doi: $10.1038 /$ nature 05429

Urban, M. C., Tewksbury, J. J., and Sheldon, K. S. (2012). On a collision course: competition and dispersal differences create no-analogue communities and cause extinctions during climate change. Proc. R. Soc. B Biol. Sci. 279, 2072-2080. doi: 10.1098/rspb.2011.2367

Valiente-Banuet, A., Aizen, M. A., Alcántara, J. M., Arroyo, J., Cocucci, A., Galetti, M., et al. (2015). Beyond species loss: the extinction of ecological interactions in a changing world. Funct. Ecol. 29, 299-307. doi: 10.1111/1365-2435.12356

Visser, M. E., Adriaensen, F., van Balen, J. H., Blondel, J., Dhondt, A. A., van Dongen, S. et al. (2003). Variable responses to large-scale climate change in European Parus populations. Proc. R. Soc. B Biol. Sci. 270, 367-372. doi: 10.1098/rspb.2002.2244

Visser, M. E., and Both, C. (2005). Shifts in phenology due to global climate change: the need for a yardstick. Proc. R. Soc. B Biol. Sci. 272, 2561-2569. doi: 10.1098/rspb.2005.3356

Visser, M. E., te Marvelde, L., and Lof, M. E. (2012). Adaptive phenological mismatches of birds and their food in a warming world. J. Ornithol. 153, S75-S84. doi: 10.1007/s10336-011-0770-6

Visser, M. E., van Noordwijk, A. J., Tinbergen, J. M., and Lessells, C. M. (1998). Warmer springs lead to mistimed reproduction in great tits (Parus major). Proc. R. Soc. B Biol. Sci. 265, 1867-1870. doi: 10.1098/rspb.1998.0514

Wagner, R. H., and Danchin, E. (2010). A taxonomy of biological information. Oikos 119, 203-209. doi: 10.1111/j.1600-0706.2009.17315.x

Walther, G. R. (2010). Community and ecosystem responses to recent climate change. Proc. R. Soc. B Biol. Sci. 365, 2019-2024. doi: 10.1098/rstb.2010.0021

Walther, G. R., Post, E., Convey, P., Menzel, A., Parmesan, C., Beebee, T. J. C., et al. (2002). Ecological responses to recent climate change. Nature 416, 389-395. doi: $10.1038 / 416389$ a

Winkel, W., and Hudde, H. (1997). Long-term trends in reproductive traits of tits (Parus major, P-caeruleus) and pied flycatchers ficedula hypoleuca. J. Avian Biol. 28, 187-190. doi: 10.2307/3677313

Wittwer, T., O’Hara, R. B., Caplat, P., Hickler, T., and Smith, H. G. (2015). Longterm population dynamics of a migrant bird suggests interaction of climate change and competition with resident species. Oikos 124, 1151-1159. doi: 10.1111/oik.01559

Wuethrich, B. (2000). Ecology - How climate change alters rhythms of the wild. Science 287, 793. doi: 10.1126/science.287.5454.793

Conflict of Interest Statement: The author declares that the research was conducted in the absence of any commercial or financial relationships that could be construed as a potential conflict of interest.

Copyright (c) 2016 Parejo. This is an open-access article distributed under the terms of the Creative Commons Attribution License (CC BY). The use, distribution or reproduction in other forums is permitted, provided the original author(s) or licensor are credited and that the original publication in this journal is cited, in accordance with accepted academic practice. No use, distribution or reproduction is permitted which does not comply with these terms. 